\title{
MORFOLOGIA DO SOLO E DA VEGETAÇÃO EM UMA TOPOSSEQUÊNCIA ADJACENTE À USINA HIDRELÉTRICA DE TUCURUÍ, PARÁ, BRASIL
}

\author{
Alexandre Leão Gonçalves ${ }^{1}$; Vanessa Maria Silva da Cruz1; Elielton de Sousa \\ Ramos $^{1}$, Sávio Góes Sarges ${ }^{1}$, Alisson Rodrigo Souza Reis²
}

'Discentes de Engenharia Florestal, Universidade Federal do Pará (eng.alexandregoncalves@outlook.com)

2Docente da Faculdade de Engenharia Florestal, Universidade Federal do Pará

Recebido em: 08/04/2017 - Aprovado em: 10/06/2017 - Publicado em: 20/06/2017 DOI: 10.18677/EnciBio 2017A75

\begin{abstract}
RESUMO
O objetivo desse trabalho foi descrever as características morfológicas do solo e da vegetação, relacionando-as com a topografia de uma área adjacente à Usina Hidrelétrica (UHE) de Tucuruí-PA. Para isso, foram realizadas coletas de solo em quatro pontos, dispostos em um transecto com distância de $25 \mathrm{~m}$ entre si. Em cada ponto foram coletadas amostras em quatro diferentes profundidades: 0-20, 20-40, 40-60 e 60-80 cm. As amostras foram analisadas no laboratório de solos da Faculdade de Engenharia Sanitária e Ambiental da Universidade Federal do Pará, utilizando o fluxograma de Norticliff para a textura e a carta de Munsell para as cores. Para amostragem da vegetação foi alocado uma parcela de $25 \times 100 \mathrm{~m}$, no mesmo sentido do transecto das coletas do solo, sendo inventariados todos os indivíduos com DAP $\geq 10 \mathrm{~cm}$. Considerou-se: o porte, o fuste (tipo, base e forma) e o tipo de raiz. A textura de solo predominante foi a Franco Argilo Siltosa e as cores Weak Red e Dusky Red. Em relação à vegetação tiveram maior ocorrência: árvores de pequeno porte, fuste do tipo cilíndrico, base do fuste reta, forma do fuste tortuosa e raiz do tipo subterrânea. Constatou-se que há influência da topografia do terreno sobre as características da vegetação e do solo.
\end{abstract}

PALAVRAS-CHAVE: floresta secundária, textura, topografia.

\section{SOIL AND VEGETATION MORPHOLOGY AT AN ADJACENT TOPOSEQUENCE THE HYDROELECTRIC PLANT OF TUCURUÍ, PARÁ, BRAZIL}

\begin{abstract}
This research aimed to describe the morphologic features of the soil and the vegetation, relating them to an adjacent area around the Hydroelectric Power Plant (UHE) of Tucuruí, PA. In order to fulfill this goal, a collection was carried out in four points inside a transect with $25 \mathrm{~m}$ of distance between them. In each point it was collected samples in four different profundities: 0-20, 20-40, 40-60 and 60-80 cm. The samples were analyzed at the soil laboratory of the Sanitary and Environmental Engineering School of the University of Para, using the Norticliff flowchart for texture and the Munsell chart for colors. To the sampling of the vegetation, it was allocated a parcel of $25 \times 100 \mathrm{~m}$, In the same sense of the transect of the soil collections, and all the individuals with a diameter at breast height $\geq 10 \mathrm{~cm}$ were catalogued. It was taken in consideration the size, the stem (type, base and form) and the type of the
\end{abstract}


root. The predominant soil texture was a Franco Argilo Siltosa and the colors were Weak Red and Dusky Red. Concerning the vegetation, the following types were prevalent: small-sized trees, cylindrical stem with straight base and sinuous form and underground roots. The conclusion reached was, therefore, that the land topography influences the features of both soil and vegetation.

KEYWORDS: secondary forest, texture, topography.

\section{INTRODUÇÃO}

A usina hidrelétrica de Tucuruí começou a ser construída na década de 70 e no ano de 1984 já se encontrava em operação, e desde a sua instalação, a usina trouxe severos impactos para o entorno, onde grandes áreas foram alagadas, ocasionando perda da fauna e da flora (PINTO, 2012).

Em razão do represamento do rio Tocantins, formou-se um lago com aproximadamente $2.840 \mathrm{~km}^{2}$, que cobriu cerca de 200 mil hectares de floresta primária (BORGES et al., 2004). Como resultado disso, surgiram 1.100 ilhas na bacia do Tocantins, locais que eram áreas de pastagens, e que após a inundação foram abandonadas dando origem a florestas secundárias (PINTO, 2012).

De modo geral, as florestas têm importância vital para o equilíbrio ecológico e ambiental do planeta, uma vez que proporcionam condições fundamentais para a existência da vida, tais como: amenização do clima, conservação dos recursos hídricos, manutenção da biodiversidade e a reciclagem natural dos solos (TERRA et al., 2015; ARRUDA et al., 2015).

O solo é um dos principais componentes da floresta, sendo um recurso que cumpri funções importantes como o escoamento e infiltração da água da chuva, o armazenamento e a ciclagem de nutrientes para as plantas, e ainda, tem ação filtrante e protetora da qualidade da água e do ar (JUNIOR et al., 2015). O estudo do solo engloba várias categorias de pesquisas que são essenciais para a percepção do seu funcionamento e das formas de uso que o torna passível a degradação, e que implicam nas futuras tomadas de decisão em relação ao seu manejo.

Alguns aspectos morfológicos como cor e textura são parâmetros utilizados na identificação (MEDEIROS et al., 2013) cada cor pode representar um determinado tipo de solo, podendo também expressar variados tipos de vegetação, pois os componentes do solo juntamente com o relevo podem influenciar no crescimento da planta, alterando sua forma e estrutura (REIS et al., 2007).

Segundo CAMPOS et al. (2012) as relações entre solos, relevo e vegetação caracterizam-se por serem interdependentes, uma vez que as condições de drenagem e a variação dos solos interferem nas formações vegetais, de outro modo, as condições de relevo influenciam em várias propriedades dos solos, como estrutura, porosidade, densidade, e até mesmo no teor de nutrientes.

Os estudos do solo e da vegetação com relação ao relevo mostram-se importantes, pois oferecem subsídios para a compreensão da forma de funcionamento dos mesmos em diferentes ambientes (JUNIOR et al., 2015). De acordo com TERRA et al. (2015), pesquisas dessa natureza tornam possível a relação entre aspectos do solo, da paisagem, levando em consideração a realidade do relevo do terreno, de modo a transmitir uma visão integrada dos componentes destes ambientes e as suas particularidades.

Diante do exposto, fica evidente a relevância das investigações sobre o solo e a vegetação para a avaliação das formas de uso e manejo desses recursos, tomando como base os aspectos de influência do relevo sobre os mesmos. Sendo 
assim, O objetivo desse trabalho foi descrever as características morfológicas do solo e da vegetação, relacionando-as com a topografia de uma área adjacente à Usina Hidrelétrica (UHE) de Tucuruí - PA.

\section{MATERIAL E MÉTODOS}

O estudo foi desenvolvido no município de Tucuruí, Pará, no Parque Ecológico Sebastião Camargo, situado próximo ao segundo canal das eclusas da Usina Hidrelétrica de Tucuruí (UHE), sob as coordenadas: latitude: $3^{\circ} 47.579 ' S$ e longitude: $49^{\circ} 39.409^{\prime} \mathrm{O}$ (figura 1).

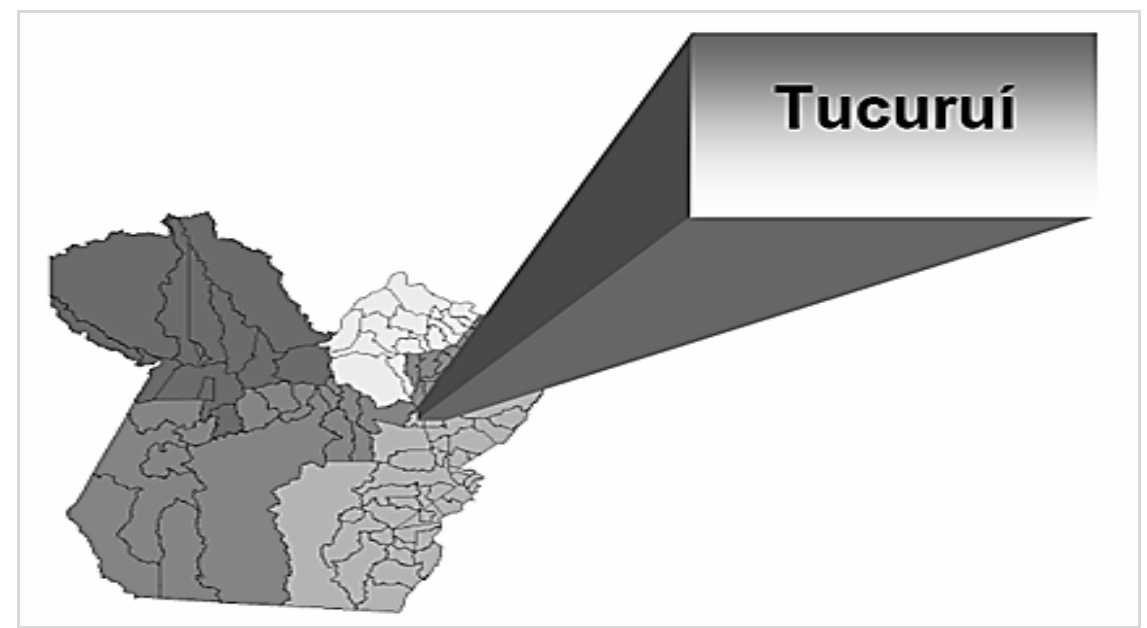

FIGURA 1. Localização geográfica de Tucuruí, Pará.

Fonte: PDRS (2013).

O parque possui cerca de 400 hectares de área verde, com vegetação predominantemente composta por florestas secundárias e de terra firme. A vegetação predominante no município de Tucuruí é a de Floresta Tropical Úmida, com os subtipos: Floresta Aberta Latifoliada, Densa de Platô, Densa de Terraços, Floresta Submontana, em relevo aplainado. O clima insere-se na categoria de equatorial super-úmido, tipo Ami, da classificação de Köppen, no limite de transição para o tipo Aw (PDRS, 2013). Possui temperatura média anual de $26{ }^{\circ} \mathrm{C}$, apresentando média máxima em torno de $32{ }^{\circ} \mathrm{C}$ e mínima de $22 \stackrel{\circ}{\circ} \mathrm{C}$. A umidade relativa é elevada e apresenta oscilações entre a estação mais chuvosa e a seca respectivamente, de 100 a 52\%, sendo a média real de $78 \%$ (IBGE, 2015).

As coletas de solo foram realizadas com auxílio de trado do tipo holandês em quatro pontos, sendo P1, P2, P3 e P4 respectivamente (figura 2), e dispostos em um transecto com distância de $25 \mathrm{~m}$ entre si. 


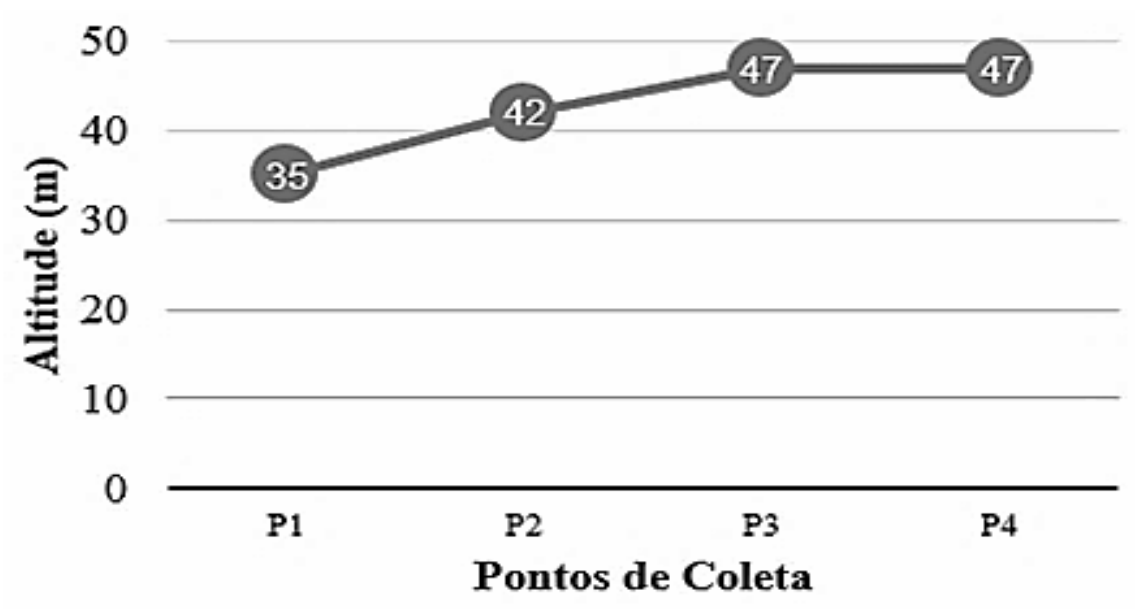

FIGURA 2. Perfil de elevação entre $P 1$ e $P 4$ na topossequência adjacente à UHE de Tucuruí, Pará.

Os pontos foram devidamente georreferênciados com auxílio de GPS (Global Position System). Em cada ponto foram coletadas quatro amostras de solo em diferentes profundidades: 0-20 cm, 20-40 cm, 40-60 cm e 60-80 cm. Após a coleta, as amostras de solos foram acondicionadas em sacos plásticos de dois quilos, devidamente identificadas, e em seguida foram levadas ao laboratório de solos da Faculdade de Engenharia Sanitária e Ambiental da Universidade Federal do Pará Campus Tucuruí, para realizarem-se as análises de cor com o auxílio da carta de Munsell e de textura determinada através do fluxograma de Norticliff conforme os métodos de ROWELL (1994).

Para amostragem da vegetação foi alocada uma parcela com base no transecto utilizado para coleta do solo, com dimensão de $25 \times 100 \mathrm{~m}$, totalizando 0,25 ha, onde foram inventariados todos os indivíduos com diâmetro à altura do peito (DAP) igual ou superior a $10 \mathrm{~cm}$, com o auxílio de fita métrica. Os indivíduos com DAP até $15 \mathrm{~cm}$ foram classificados como de pequeno porte, os com diâmetro de 15 a $50 \mathrm{~cm}$ foram contabilizados como porte médio, já os com mais de $50 \mathrm{~cm}$ se enquadraram como grande porte.

Assim, foram anotadas as seguintes informações de cada indivíduo: DAP, porte (estimando-se através do DAP), tipo, base e forma do fuste, bem como o tipo de raiz. As análises dos parâmetros em relação ao fuste e a raiz foram feitas com base nos fundamentos de dendrologia, de acordo com MARCHIORI (2013). E todas essas informações foram utilizadas para fazer a caracterização macromorfológicas dos aspectos físicos das árvores.

\section{RESULTADOS E DISCUSSÃO}

De maneira geral, a textura predominante em todas as profundidades de todos os pontos foi a franco argilo siltosa (tabela 1). Nesse parâmetro houve pouca variação entre os tipos de classificação de textura franca, essas classificações e seus respetivos nomes estão diretamente ligados à predominância de partículas (em $\mathrm{g} \mathrm{kg}^{-1}$ de solo) de determinada fração granulométrica na composição desses solos. 
TABELA 1. Análise morfológica geral das amostras de solo em cada profundidade.

\begin{tabular}{|c|c|c|}
\hline $\begin{array}{c}\text { PROFUNDIDADE } \\
(\mathrm{cm})\end{array}$ & TEXTURA & COR \\
\hline $0-20$ & $\begin{array}{c}\text { Areia Franca }(25 \%) \\
\text { Franca }(25 \%) \\
\text { Franco Argilo Siltosa (50\%) }\end{array}$ & $\begin{array}{c}\text { Weak Red }(50 \%) \\
\text { Dusky Red }(25 \%) \\
\text { Grayish Brown (25\%) }\end{array}$ \\
\hline $20-40$ & Franco Argilo Siltosa (100\%) & $\begin{array}{c}\text { Weak Red (25\%) } \\
\text { Red (25\%) } \\
\text { Yellowish Brown (25\%) } \\
\text { Light Reddish Brown (25\%) }\end{array}$ \\
\hline $40-60$ & $\begin{array}{c}\text { Franco Siltoso (75\%) } \\
\text { Franco Argilo Siltosa (25\%) }\end{array}$ & $\begin{array}{c}\text { Dusky Red }(25 \%) \\
\text { Olive Yellow }(25 \%) \\
\text { Brownish Yellow }(25 \%) \\
\text { Reddish Yellow }(25 \%)\end{array}$ \\
\hline $60-80$ & $\begin{array}{l}\text { Franco Argilo Siltosa }(50 \%) \\
\quad \text { Franco Siltoso }(50 \%)\end{array}$ & $\begin{array}{c}\text { Dusky Red (25\%) } \\
\text { Strong Brown (25\%) } \\
\text { Brownish Yellow }(25 \%) \\
\text { Yellowish Brow }(25 \%) \text { n }\end{array}$ \\
\hline
\end{tabular}

Segundo FAGERIA \& STONE (2006), os solos de textura franca são uma mistura equilibrada de partículas de areia, silte e argila, desse modo, se constituem em uma textura média e exibem propriedades leves e pesadas em proporções aproximadamente iguais. Dentre as amostras, apenas uma apresentou textura arenosa (areia franca), sendo que essa foi coletada na profundidade mais superficial $(0$ a $20 \mathrm{~cm})$, no primeiro ponto de coleta $(\mathrm{P} 1)$. Relacionando essa textura com a profundidade na qual foi identificada, REIS et al. (2007) enfatizam que não é corriqueiro a identificação de solos arenosos nas camadas mais superficiais.

A única amostra que apresentou solo do tipo arenoso foi coletada na menor altitude amostral e próxima a um córrego. Esse resultado pode ser devido à acumulação relativa da fração de areia, em consequência de uma exportação intensa até a rede hidrográfica de materiais solúveis ou de partículas finas do solo ocasionada pela permanência de água neste local durante a estação úmida. Neste sentido, REIS et al. (2007) explicam essa relação, frisando que o acúmulo de areia, com relação ao relevo, se dá no sentido da alta vertente para a baixa vertente.

De acordo com CAMBRONERO et al. (2011), os solos arenosos não são indicados para o plantio de espécies arbóreas devido as características de ausência de formação de agregados, baixa capacidade de troca catiônica (CTC), e espaços porosos grandes. Esses fatores podem ocasionar problemas como a diminuição da água disponível no solo, a redução do crescimento vegetal, além de contribuir para o aumento da lixiviação de nutrientes do solo e erosão, principalmente, em áreas declivosas.

Em se tratando da cor, as amostras apresentaram bastante variação em quase todos os pontos de coleta e nas diferentes profundidades. As cores mais frequentes foram Weak Red e Dusky Red (Tabela 1), a primeira com coloração tendendo para um vermelho fraco, e esta última para um vermelho sombrio. Logo em seguida, Brownish Yellow e Yellowish Brown aparecem empatadas no segundo lugar da ocorrência de cores.

SPANNER et al. (2014) inferem que a coloração dos solos é determinada por três fatores importantes: matéria orgânica, conteúdo de sílica e compostos de ferro e 
cada cor representa um indicativo para o solo, sendo assim, cores vermelhas indicam a existência de hematita caracterizando boa drenagem e aeração do solo, já as cores escuras evidenciam a presença de matéria orgânica. Assim, visualiza-se a relevância do estudo e conhecimento da coloração do solo para a observação de indicadores pertinentes ao desenvolvimento dos vegetais, bem como em outras formas de uso deste recurso.

CAMPOS et al. (2010) esclarecem que o reconhecimento das cores do solo pode ser uma tarefa complexa, e explica que devido os limites estabelecidos para a classificação dos solos e das divergências na determinação da cor, pesquisadores podem classificar um mesmo solo de forma diferente. A figura 3 ilustra a análise da ocorrência das cores nos solos estudados em termos percentuais, considerando o total de cores, todos os pontos de coleta e todas as profundidades de tradagem.
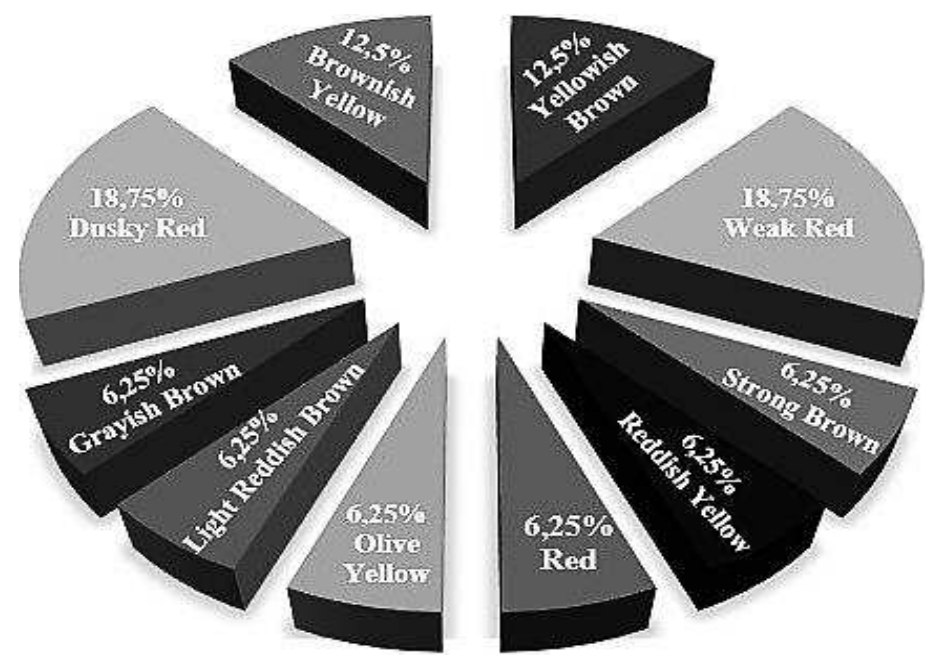

FIGURA 3. Incidência geral das cores das amostras de solos coletados na topossequência adjacente à UHE de Tucuruí, Pará.

Apesar da área amostral ser pequena, os resultados evidenciaram que há diversidade de cores, bem como a considerável variação dos cromas. Desses resultados, a carta de Munsell indica que: Weak Red representa 7.5R com cromas 4/2 e 5/3 e 2.5YR com croma 5/2; Dusky Red é indicado por 7.5R e cromas 3/3 e 3/4 e 10R com número cromático 3/2; Grayish Brown corresponde a 10YR com croma $5 / 2$; Red é concernente a $10 \mathrm{R}$ e número cromático 5/6; Yellowish Brown equivale a 10YR e cromas 5/4 e 5/8; 2.5YR com croma 6/4 é de Light Reddish Brown; Olive Yellow representa 2.5Y com croma 6/8; Brownish Yellow é indicado por 10YR e cromas 6/6 e 6/8; Reddish Yellow é correspondente a 5YR e croma 7/8; 7.5YR e croma 5/8 é equivalente a Strong Brown.

De modo geral, as cores tiveram variação do vermelho claro ao marrom forte, com matiz de 2.5YR a 7.5YR, e do castanho avermelhado ao amarelo acinzentado, com matiz 2.5YR a 2.5Y. Em um estudo realizado numa área de topossequência no Distrito Federal, JUNIOR et al. (2015) obtiveram resultados semelhantes a estes no que concerne a variação de matiz. BARBOSA et al. (2009) explicam que variações desse tipo se dão pelo tipo de material de origem ou pelo regime de drenagem interna no perfil do solo.

Já CAMPOS et al. (2010) identificaram numa área de topossequência na região de Manicoré uma escala de variação entre 0 vermelho e 0 amarelo, estabelecendo-se a seguinte ordem: 10R, 2.5YR, 5.0YR, 7.5YR, 10YR e 2.5Y. Algumas cores não apresentaram variação em seus respectivos cromas, isso se deu ENCICLOPÉDIA BIOSFERA, Centro Científico Conhecer - Goiânia, v.14 n.25; p.944 2017 
devido a cada uma dessas terem sido constatadas em apenas um ponto de coleta e em uma única profundidade. Sendo essas: Grayish Brown (P3, 0-20 cm), Red (P2, 20-40 cm), Light Reddish Brown (P4, 20-40 cm), Olive Yellow (P2, 40-60 cm), Reddish Yellow (P4, 40-60 cm), e Strong Brown (P2, 60-80 cm).

Segundo TERRA et al. (2015), quando se trata de ecossistemas florestais, é inegável a existência de uma forte relação entre os atributos do solo com a vegetação. É possível investigar essa relação através da observação de parâmetros pedológicos, dendrológicos e fitossociológicos que possam evidenciar isso. Para ARRUDA et al. (2015) a compreensão das correlações existentes entre o solo e a vegetação é fundamental para o estudo do comportamento de ambos no ambiente, e da forma de interação do ambiente com os mesmos.

$\mathrm{Na}$ análise da vegetação foram amostrados 159 indivíduos. As árvores de pequeno porte foram as que tiveram maior ocorrência $(64,15 \%)$, seguida pelas de porte médio $(28,30 \%)$, e por último, as de grande porte $(7,55 \%)$. O fato do porte das árvores ser representado majoritariamente por indivíduos de pequeno porte está ligado às características da vegetação do local, que é de florestal secundária em estágio de regeneração, com histórico de ter sofrido severas perturbações por ação antrópica.

Quanto aos parâmetros analisados em relação ao fuste, foi predominante a quantidade de indivíduos que apresentaram fuste do tipo cilíndrico, a base reta e os que têm a forma tortuosa (tabela 2).

TABELA 2. Quantificação dos parâmetros analisados em relação ao fuste das árvores amostradas na topossequência adjacente à UHE de Tucuruí, Pará.

\begin{tabular}{|cc|cc|cc|}
\hline Tipo & Quantidade & Base & Quantidade & Forma & Quantidade \\
\hline Cilíndrico & 135 & Reta & 71 & Reto & 54 \\
\hline Elíptico & 3 & Dilatada & 70 & Tortuoso & 94 \\
\hline Acanalado & 10 & Digitada & 16 & Inclinado & 11 \\
\hline Fenestrado & 5 & Acanalada & 2 & & \\
\hline Irregular & 6 & & & & \\
\hline
\end{tabular}

Observou-se que existe uma relação direta dos aspectos do fuste com a declividade da topografia, sendo que à medida que aumentou altitude do terreno, houve maior ocorrência de indivíduos com a forma do fuste inclinado. Neste sentido, JUNIOR et al. (2015) afirmam que o relevo influencia na formação do solo, fundamentalmente, pela sua interferência na dinâmica da água e nos processos de erosão e sedimentação, e consequentemente esses fatores terão influência na formação dos povoamentos florestais.

Desse modo, visualiza-se a importância de investigações dessa natureza para análise da forma em que a topografia se reflete na formação da vegetação e nos aspectos do solo. Para TERRA et al. (2015), o estudo dos solos com relação à topografia permite uma visão global e integrada dos vários componentes da paisagem e das atividades antrópicas na área, permitindo o estabelecimento de relações entre atributos dos solos, relevo e paisagem. Em relação aos tipos de raízes, constatou-se que as subterrâneas foram as que mais ocorreram e as do tipo adventícias tiveram a menor incidência na área estudada (figura 4). 


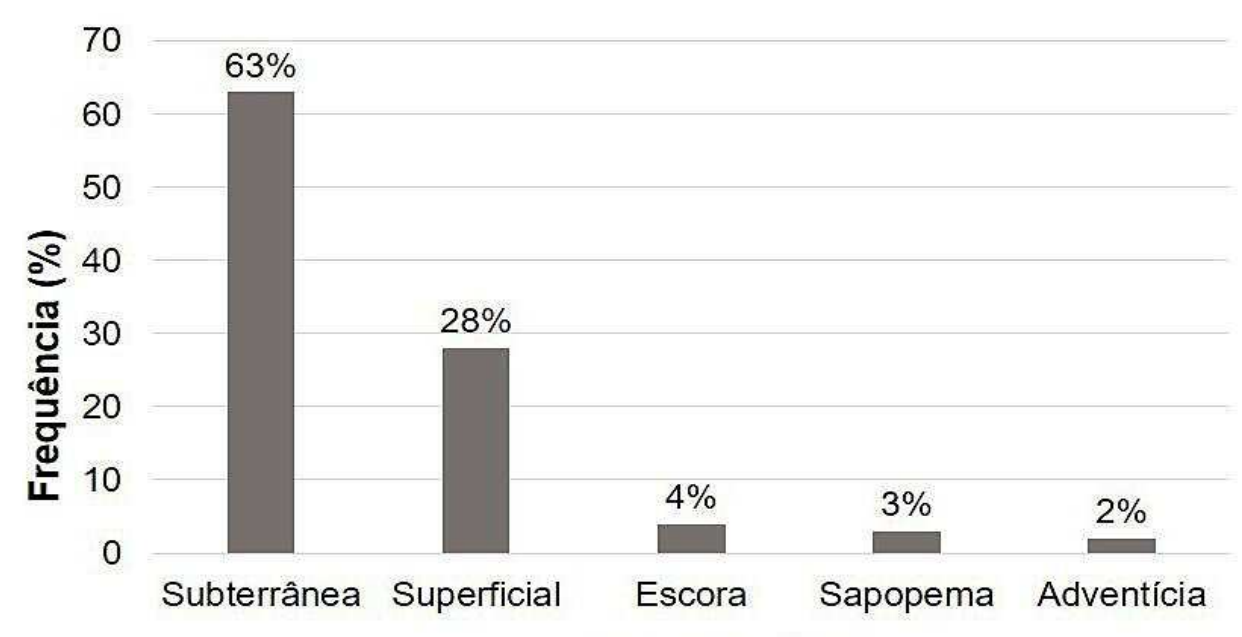

Tipos de raízes

FIGURA 4. Ocorrência dos tipos de raízes das árvores amostradas na topossequência adjacente à UHE de Tucuruí, Pará.

Além dos aspectos do fuste, a topografia também influencia na formação das raízes. Um fator que evidenciou essa relação foi que quanto maior a altitude, proporcionalmente aumentou o aparecimento de raízes subterrâneas, e em contrapartida, quanto maior foi o declive mais sugiram indivíduos com raízes superficiais. Essas adaptações dos vegetais ocorreram devido à necessidade de uma boa fixação no solo, em razão das características topográficas de forte inclinação do terreno, facilmente observadas no perfil de elevação (figura 2).

Apesar da identificação de poucos indivíduos com essa característica, as raízes escoras não apresentaram um padrão de incidência em relação à topografia, aparecendo em diferentes altitudes. Em uma área de topossequência no município de Altamira-PA, SPANNER et al. (2014) obtiveram resultados semelhantes onde a ocorrência de raízes do tipo superficial foi proporcional ao aumento do declive, entretanto, o aparecimento de raízes subterrâneas foi equivalente a elevação do terreno. O mesmo ocorreu com as raízes do tipo escora, cujo seu aparecimento não obedeceu a padrões de tendência.

Neste sentido, MEIRELES et al. (2012) explicam que a paisagem é um condicionador dos aspectos do ambiente, sendo que a sua configuração tem relação íntima com o relevo, podendo estabelecer formações e condições específicas em diferentes regiões. Para uma avaliação mais precisa, a figura 5 ilustra a incidência dos tipos de raízes em relação à topografia ao longo da área investigada. 


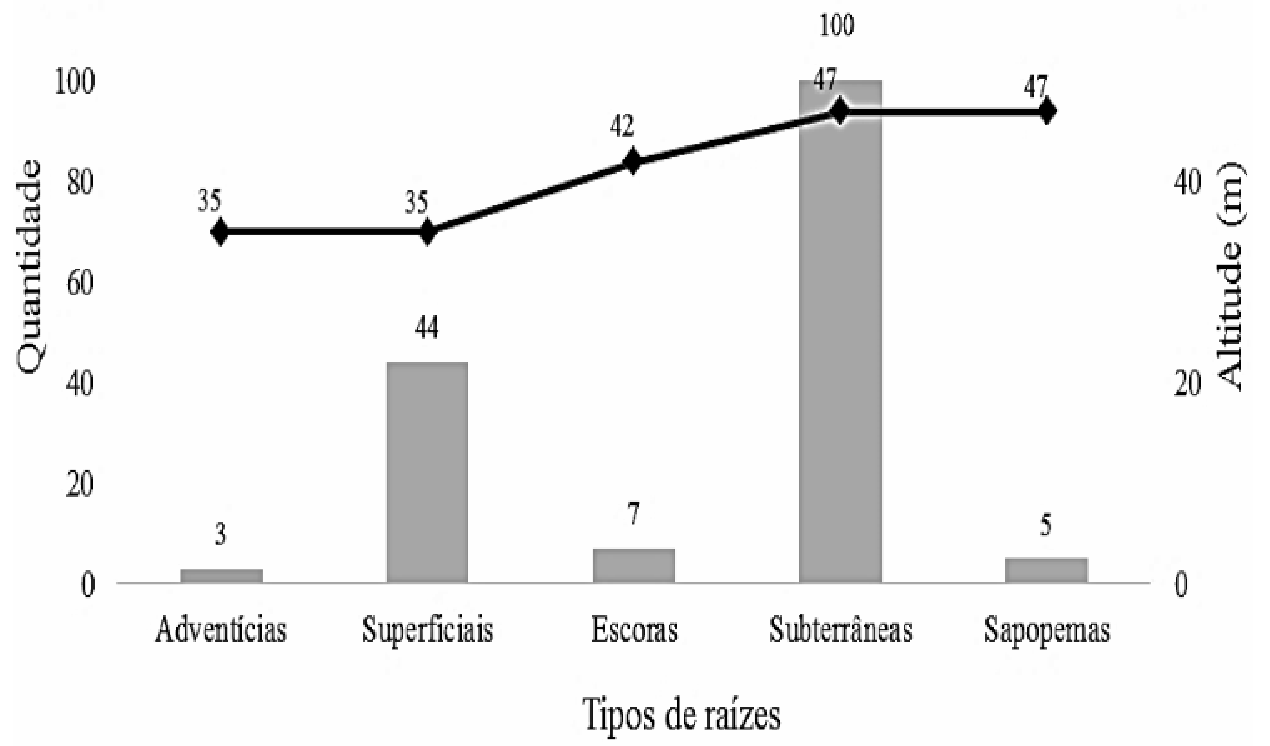

FIGURA 5. Incidência dos tipos de raízes das árvores amostradas em relação à topografia do terreno adjacente à UHE de Tucuruí, Pará.

Analisando a figura 5 é possível verificar a clara proporcionalidade do aparecimento dos tipos de raízes em função do aumento ou diminuição da altitude. Observa-se que as raízes dos tipos sapopema e subterrânea têm maior incidência na maior altitude do terreno, constatando que essas espécies arbóreas investem bastante em sustentação devido à inclinação da área. Já as raízes dos tipos: superficial, escora e adventícia ocorrem nas menores altitudes, mostrando um padrão de preferência das árvores que possuem esses tipos de raiz por áreas com características de se tornarem alagadas na época chuvosa.

Segundo ARRUDA et al. (2015), a relação entre as formações vegetais e a altitude, pode ser interpretada como geoformas na escala das diferentes paisagens. CAMPOS et al. (2010) afirmam que as condições topográficas se refletem nos aspectos da vegetação e do solo, sendo que à medida que ocorre a elevação do terreno, a fisionomia do ambiente muda, e tende a ter uma formação de aspecto mais uniforme. PAULA et al. (2012) ressaltam que o conhecimento dos atributos do solo e do relevo auxilia no manejo adequado do local de trabalho, e pode auxiliar diretamente no aumento da produtividade durante o ciclo de corte em florestas plantadas.

\section{CONCLUSÃO}

A topografia do terreno exerce influencia sobre as características da vegetação e do solo. De forma que os indivíduos tendem a se agrupar por caracteres comuns e proporcionalmente à mudança da altitude, assim como ocorre mudança nos aspectos morfológicos do solo ao longo do relevo.

\section{REFERÊNCIAS}

ARRUDA, D. M.; SCHAEFER, C. E. G. R.; MORAES, M. L. B. de. Relações entre atributos do solo e vegetações da região ecotonal do médio rio São Francisco, Brasil. Revista Brasileira de Ciência do Solo, Viçosa, v. 39, n. 3, p. 1524-1532, 
nov./dez. 2015. Disponível em: <http://dx.doi.org/10.1590/01000683rbcs20150241>. doi: 10.1590/01000683rbcs20150241

BARBOSA, I. O.; LACERDA, M. P. C.; BILICH, M. R. Relações pedomorfogeológicas nas chapadas elevadas do Distrito Federal. Revista Brasileira de Ciência do Solo, Viçosa, v. 33, n. 5, p. 1373-1383, set./out. 2009. Disponível em: <http://dx.doi.org/10. 1590/S0100-06832009000500029>. doi: 10.1590/S0100-06832009000500029.

BORGES, A. I.; TAVARES, A. C. C., LISBOA, R. C. L. Briófitas da ilha de germoplasma, reservatório de Tucuruí, Pará, Brasil. Revista Acta Botânica Brasílica, São Paulo, v. 18, n. 3, p. 01-04, jul./set. 2004. Disponível em: <http://dx.doi.org/10.1590/S0102-33062004000300026>. doi: 10.1590/S0102-33062 004000300026.

CAMBRONERO, Y. C.; MAIA, C. M. B. de F.; DEDECEK, R. A.; HANSEL, F. A. Influência da concentração de extratos hidrofóbicos na repelência à água em solos arenosos. Revista Pesquisa Florestal Brasileira, Brasília, v. 31, n. 65, p. 01-08, set./out. 2011. Disponível em: <http://dx.doi.org/10.4336/2011.pfb.31.65.01>. doi: 10.4336/2011.pfb.31.65.01.

CAMPOS, M. C. C.; RIBEIRO, M. R.; SOUSA JÚNIOR, V. S.; RIBEIRO FILHO, M. R.; ALMEIDA, M. C. Topossequência de solos na transição Campos NaturaisFloresta na região de Humaitá, Amazonas. Revista Acta Amazônica, Manaus, v. 42, n. 3, p. 387-398, set. 2012. Disponível em: <http://www.scielo.br/pdf/aa/v42n3/a1 1v42n3.pdf>. Acesso em: 30 jan. 2017.

CAMPOS, M. C. C.; RIBEIRO, M. R.; SOUSA JÚNIOR, V. S.; RIBEIRO FILHO, M. R.; COSTA, E. U. C. Segmentos de vertente e atributos do solo de uma topossequência na região de Manicoré, AM. Revista Ciência Agronômica, Fortaleza, v. 41, n. 4, p. 501-510, nov./dez. 2010. Disponível em: <http://dx.doi.org/1 0.1590/S1806-66902010000400001>. doi: 10.1590/S1806-66902010000400001.

FAGERIA, N. K.; STONE, L. F. Qualidade do solo e meio ambiente. v. 1. 21 ed. Santo Antônio de Goiás: EMBRAPA, 2006. 35 p.

IBGE. Estatísticas do município de Tucuruí, Pará, Brasil. Instituto Brasileiro de Geografia Estatística, 2015. Disponível em: <http://cidades.ibge.gov.br/xtras/perfil.ph p?codmun=150810>. Acesso em: 20 dez. 2016.

JUNIOR, F. R.; ARAÚJO, L. G.; SOUZA, R. Q. DE.; BATISTA, F. P. DA S.; OLIVEIRA, D. N. S. DE.; LACERDA, M. P. C. Relações solo-paisagem em topossequências na fazenda água limpa, Distrito Federal. Revista Nativa, Sinop, v. 3, n. 1, p.27-35, jan./mai. 2015. Disponível em: <http://dx.doi.org/10.14583/2318-767 0.v03n01a05> doi: 10.14583/2318-7670.v03n01a05.

MARCHIORI, J. N. C. Elementos de Dendrologia. v. 1. 3 ed. Santa Maria: UFSM, 2013. 216 p.

MEDEIROS, P. S. C. de; NASCIMENTO, P. C. do; INDA, A. V.; SILVA, D. S. da. Caracterização e classificação de solos graníticos em topossequência na região sul 
do Brasil. Revista Ciência Rural, Santa Maria, v. 43, n. 7, p. 1210-1217, jul. 2013. Disponível em: <http://www.scielo.br/pdf/cr/v43n7/a20913cr6607.pdf>. Acesso em: 15 fev. 2017.

MEIRELES, H. T.; JÚNIOR, M. J.; CAMPOS, M. C. C.; PEREIRA, G. T. Relações solo-paisagem em topossequência de origem basáltica. Revista Pesquisa Agropecuária Tropical, Goiânia, v. 42, n. 2, p. 129-136, abr./jun. 2012. Disponível em: <http://dx.doi.org/10.1590/S1983-40632012000200001>. doi: 10.1590/S1983-40 632012000200001.

PAULA, R. R.; PEREIRA, M. G.; SANTIAGO, R. R.; AMORIM, H. B. Propriedades edáficas e desenvolvimento de eucalipto em topossequência na Flona Mário XavierRJ. Revista Floresta e Ambiente, Seropédica, v. 19, n. 3, p. 344-351, jul./set. 2012. Disponível em: <http://dx.doi.org/10.4322/floram.2012.040>. doi: 10.4322/floram.201 2.04 .

PDRS. Plano de desenvolvimento regional sustentável do lago de Tucuruí. Governo do estado do Pará, 2013. Disponível em: <http://www.mi.gov.br/c/document library/get_file?uuid=0a6eac82-0b58-40bf-a60e-c80828c0ec90\&groupld=10157>. Ácesso em: 18 dez. 2016.

PINTO, L. F. De Tucuruí a Belo Monte: a história avança mesmo?. Boletim do Museu Paraense Emílio Goeldi - Ciências humanas, Belém, v. 7, n. 3, p. 778782, set./dez. 2012. Disponível em: <http://dx.doi.org/10.1590/S1981-812220120003 00010>. doi: 10.1590/S1981-81222012000300010.

REIS, M. DA S.; FERNANDES, A. R.; GRIMALDI, C.; SARRAZIN, M.; GRIMALDI, M. Variação da composição granulométrica e orgânica do solo em uma topossequência da microrregião de Marabá-PA. Boletim do Museu Paraense Emilio Goeldi Ciências Naturais, Belém, v. 2, n. 3, p. 33-44, set./dez. 2007. Disponível em: <http:// www.museu-goeldi.br/editora/bn/artigos/cnv2n3_2007/variacao(reis).pdf>. Acesso em: 08 nov. 2016.

ROWELL, D. L. Soil Science: Methods and applications. Longman Scientific \& Technical, Reino Unido, v. 66, n. 4, p. 573-574, dez. 1994. Disponível em: <http://dx.doi.org/10.1002/jsfa.2740660423>. doi: 10.1002/jsfa.2740660423.

SPANNER, G. C.; NEVES, É. S. das; NASCIMENTO, J. C. DO; MILÉO, J. A. C.; SILVA, S. A. S. da. Determinação dos aspectos morfológicos do Solo e dendrológicos da vegetação em uma topossequência, em Altamira-PA. Revista Agrarian Academy, Goiânia, v. 1, n. 2, p. 37-46, jun./set. 2014. Disponível em: <http://dx.doi.org/10.18677/Agrarian_Academy_2014_028>. doi: 10.18677/Agrarian_ Academy_2014_028.

TERRA, M. de C. N.; MELLO, J. M. de; MELLO, C. R. de. Relação espacial do carbono da vegetação e matéria orgânica do solo na Serra da Mantiqueira. Revista Floresta e Ambiente, Seropédica, v. 22, n. 4, p. 446-455, out./dez. 2015. Disponível em: <http://dx.doi.org/10.1590/2179-8087.059713>. doi: 10.1590/2179-8087.059713. 